\title{
Characteristics of CFRP/PU foam and GFRP/PU sandwich beams having initial debond between facesheet and core
}

\author{
Gurpinder Singh Dhaliwal ${ }^{1}$ (D)
}

Received: 3 June 2020 / Accepted: 21 January 2021 / Published online: 5 February 2021

(C) The Author(s) 2021 OPEN

\begin{abstract}
In the present investigation, we present, the flexural characteristics of carbon fiber reinforced polymer/polyurethane foam and glass fiber reinforced polymer/polyurethane foam sandwich beams having partial debonding between facesheet and core that acts interfacial degradation and hinders the load transfer between facesheets and core. An initial pre-crack between core and face sheet is created by placing a Teflon sheet at the interface on one end of the beams during the manufacturing of sandwich beams. A comparative analysis is carried out to study the effect of using CFRP and Eglass prepregs as face sheet material on such sandwich beams. The flexural behavior of GFRP/PU sandwich beams having initial debond is characterized and analyzed under both three- and four-point loadings. Lastly, the effect of varying the support span length on the flexural response of CFRP/PU sandwich beam having initial debond is also investigated. It was found that the degraded sandwich beams having woven CFRP facesheets have slightly higher stiffness and peak load level as compared to the sandwich beam having cross ply GFRP facesheets. GFRP/PU foam sandwich beam showed higher ductile behavior prior to progressive failure of the sandwich beam. It was observed that the crack tip of the implanted interfacial debond acts as a medium to trigger the interfacial damage followed by the shear failure of the core due to the progression of the initial crack into the core.
\end{abstract}

Keywords Initial core-facesheet debond.GFRP/foam and CFRP/foam sandwich beams · Flexural behavior characterization · Damage mechanisms

\section{Introduction}

Interfacial cracks in sandwich structures can develop due to manufacturing defects like poor face/core bonding in certain regions. The tensile and shear loads are not efficiently transferred between core and facesheet due to the presence of these defects, as a result, the load-carrying capacity of the structure is reduced. Moreover, the debonding defects also significantly affect the fatigue lifetime and overall strength of sandwich structures subjected to static or cyclic loads. Therefore, it is very crucial to investigate the debonding crack propagation in such degraded sandwich composite structures for the general application and primary load-carrying industrial structures. Many researchers have extensively investigated the flexural behavior, failure mechanisms, and strength of sandwich beams under bending loads [1-8]. However, very limited articles are available in literature characterizing the behavior of degraded sandwich beams having facesheet/core debond defects and studying damage propagation mechanisms in such composite sandwich structures under static three-point or four-point flexural loadings. The damage modes and their occurrence criteria in the unidirectional CFRP/Honeycomb and PVS foam sandwich beams were studied by Daniel et al. [1]. He investigated failure modes associated with the facesheets such as compressive failure and wrinkling failure of facesheets apart from indentation and adhesive bond failures. The collapse response of

Gurpinder Singh Dhaliwal, dz4639@wayne.edu | 'Engineering Services, Altair Product Design Inc., Troy, MI, USA. 
polyvinyl chloride (PVC) foam/composite facesheets subjected to three-point bending loading was investigated by Steeves et al. [2]. The authors reported that predictions of peak loads with the analytic expression were adequate. The beam theory becomes inappropriate and analytic models are inaccurate for sandwich beams having thick faces relative to core thickness. The sandwich beams composed of glass fiber-reinforced polymer skins and modified phenolic core material subjected to a 4-point static bending test was studied by Manalo et al. [3]. The authors studied the flexural response of these beams in both the flatwise and the edgewise positions to determine their strength and failure mechanisms.

The authors reported that these beams have a higher load-carrying capacity in the edgewise position than the flatwise position. Progressive failure of skin was common failure mode in edgewise position, whereas the shear failure of core or compressive failure of the skin accompanied by debonding between skin and core was the predominant failure in the flatwise position.

Caglayan et al. [4] investigated the flexural response of sandwich beams having polyurethane foam cores with the addition of nanomaterials such as (Carbon Nano Tubes) CNTs to them. The authors reported that a better CNT dispersion was achieved with the low viscosity dispersion media, which in turn contributed to a $13 \%$ improvement in the compressive strength of PU foams. In totally, the addition of nanomaterials to foam cores improved the core shear and face ultimate strength by approximately $30 \%$ in the composite sandwich beams. Vijay Kumar et al. [5] developed the sandwich panels to investigate the effect of thickness of facesheets, while maintaining the total thickness of beams constant as $20 \mathrm{~mm}$, on the three-point and four-point flexural characteristics of the sandwich beams. The authors presented the sandwich panel with varying thickness of facesheets and inserts that has the optimum and best stiffness values. The estimation of the physical parameters of hot-rolled steel, polyurethane foam, and polystyrene sandwich beams using measured and numeric frequency response functions (FRFs) was done by Barbieri et al. [6]. The four-point bending characteristics of the single and glue-laminated sandwich composite beams were investigated by Awad et al. [7]. The authors studied the effect of shear span ratio to depth on the shear bearing capacity and failure behavior. The buckling and dynamic behavior of sandwich beams having sisal fabric/ epoxy facings and cenosphere reinforced epoxy (syntactic foam) cores subjected to compressive loading was investigated by Waddar et al. [8]. The authors observed that fly ash cenosphere content in the cores significantly increases the natural frequencies and critical buckling load. The four-point flexural characteristics of glass fiber reinforced polymer (GFRP)/ polyurethane (PU) foam sandwich beams were investigated by Zhang et al. [9]. He investigated the effect of longitudinal, transverse, and horizontal GFRP reinforcement ribs embedded inside the PU foam core on the performance of these beams. Chandra et al. [10] studied the performance of GFRP/polyurethane sandwich beams subjected to three-point loading through finite element analysis. He analyzed the performance of beams having different skin to core weight and span to depth ratios. Tuwair et al. [11] studied the strength of sandwich beams with high- and low-density polyurethane cores with glass/ epoxy webs in trapezium shape under three-and fourpoint bending. The influence of the different foam cores and balsa wood on the mechanical performance of sandwich beams under flexural loading is characterized and compared by Fathi et al. [12]. The authors reported that the specimens containing cores with different cut patterns have higher strength and stiffness compared to the specimens having uncut cores. The bending and shear components of transverse deflections were analytically developed by Gibson [13] in sandwich beams. He also studied the effect of shear deformation on two types of sandwich beams. A comparative analysis studying the behavior of sandwich beams with and without interfacial debonding subjected to flexural loading was performed by Mohsen et al. [14].

Mohamed et al. [15] studied the manufacturing and characterization of glass reinforced composite sandwich structures with different types of cores subjected to core shear, flatwise, and edgewise compression tests. Mustafa et al. [16] studied the mechanical properties of sandwich panels manufactured from CFRP skins and various cores such as aluminum honeycomb, polypropylene honeycomb, and polyurethane rigid foam. Vadakke and Carlsson [17] studied the compressive failure mechanisms of sandwich specimens having glass/Vinylester as facesheet layers and PVC foams as a core. They observed that the short gauge length specimens mainly showed compression failure of facesheets, specimens with a thick low-density core at intermediate gauge length mainly showed anti-symmetric face wrinkling as predominant failure mode and long gauge length specimens mainly failed in global buckling. Vadakke et al. [18] presented a research investigation showing the in-plane compressive response of sandwich specimens developed by using glass/vinyl ester and carbon/epoxy polymeric materials as facesheets and polyvinyl chloride foam as a core. The sandwich specimens were manufactured by 
implanting through width face-core interfacial debond. They observed that damage morphologies of these specimens are initiated by the failure of debonded facesheet resulting from its buckling followed by fast interfacial debond enhancement towards the ends of the specimen. Aviles and Carlsson [19] conducted the in-plane compression experiments to investigate the effect of interfacial debond shape on the behavior of sandwich specimens developed by using GFRP polymeric material as facesheets, PVC foams, and balsawood materials as a core. They considered one or two circular or square interfacial debond in the specimens. They reported that the probability of interfacial failure increases with the increase in the core density, after total separation of the facesheets and core failure surfaces. They also noticed that the compressive strength of specimens is highly dependent on the debond size and core stiffness. It reduces rapidly with a surge in the debond size and lessening core stiffness. Mouritz and Thomson [20] compared the mechanical properties of GFRP/PVC sandwich panels containing interfacial cracks or impact damage subjected to edgewise compression, flexure, or shear loading conditions. Thomson et al. [21] conducted an experimental study to investigate the behavior of sandwich composites having interfacial and impact damage defects subjected to shear loading. The specimens were developed from glass-reinforced polymer skins and PVC foam core. They studied the effect of defects on the shear characteristics and damage patterns of specimens. The authors stated that the failure mode changes from wrinkling of facesheet to shear failure of a core with the interfacial crack size exceeding $20-30 \mathrm{~mm}$, due to which a rapid reduction in the static shear strength of specimens was observed.

In the light of the above-mentioned investigations, the authors intended to investigate the flexural response of sandwich beams with artificial core-facesheet debond located at one end of the beam. A comparative analysis was carried out to study the effect of using CFRP and Eglass prepregs as face sheet material on such sandwich beams. The flexural behavior of GFRP/PU sandwich beams having initial debond was characterized and analyzed under both three- and four-point loadings. Furthermore, the effect of span length on the response and failure mechanism of these sandwich beams were also investigated. The work presented in the manuscript is a continuation of the work presented in the published paper [22]. The novelty of the work presented in this manuscript with respect to the work presented in the research article [22] lies in the fact that this article goes one step ahead and lists out the effect of more critical geometric parameters, testing methods, and nature of constituents structural material such as glass fiber and carbon fiber reinforced polymer material for facesheets on flexural characteristics of the interfacially degraded sandwich composite beams. The structural organization of the article includes the details about the materials and manufacturing of specimens listed in Sect. 2, experimental methods used to characterize the flexural behavior of these beams are provided in Sect. 3, and discussions pertaining to results are enlisted in Sects. 4.1, 4.2 and 4.3. Finally, the conclusive remarks about the finding of the article are enlisted in Sect. 5.

\section{Materials and manufacturing}

Woven carbon fiber/epoxy prepreg and E-glass/epoxy prepreg were used as structural materials for face sheets and polyurethane foam for core, respectively. The supplier of E-glass/epoxy prepreg and polyurethane foam was by MAG-ias Ohio and for woven carbon fiber epoxy prepreg, known as VTM264/CF302 was CYTEC. E-glass prepreg was designed to have a cross-ply configuration where two plies were stitched together having at $0^{\circ}$ and $90^{\circ}$ orientation in each layer of prepreg. Epon 202 epoxy was the resin used in the E-glass prepreg. $2 \times 2$ twill weave fabric style with 3K FT300B40B fibers was used to manufacture the woven carbon fiber/epoxy prepreg by the supplier. The material used for core in sandwich construction was polyurethane closed-cell foam with a density of $248 \mathrm{~kg} / \mathrm{m}^{3}$. The detailed geometric dimensions of specimens prepared to study the different aspects of these sandwich beams are illustrated in Fig. 1.

Ten layers of E-glass/epoxy or woven carbon fiber epoxy prepregs were stacked up on both sides of a polyurethane foam core in order to have facesheet thickness as $5 \mathrm{~mm}$ during the development of sandwich composite panels. A Teflon sheet of thickness $0.0762 \mathrm{~mm}$ and $25.4 \mathrm{~mm}$ length was inserted between the facesheet and core on one side of the sandwich panel to simulate the initial crack. The layered sandwich panels were cured in the molding vacuum press manufactured by TMP equipment having temperature and pressure capability of $350^{\circ} \mathrm{C}$ and about $350 \mathrm{kPa}$, respectively.

The curing of the sandwich panel was performed by keeping it under vacuum and applying $344.7 \mathrm{kPa}$ pressure at $135^{\circ} \mathrm{C}$ for $20 \mathrm{~min}$. During the cooling phase of the curing cycle, the mist and water were passed over 


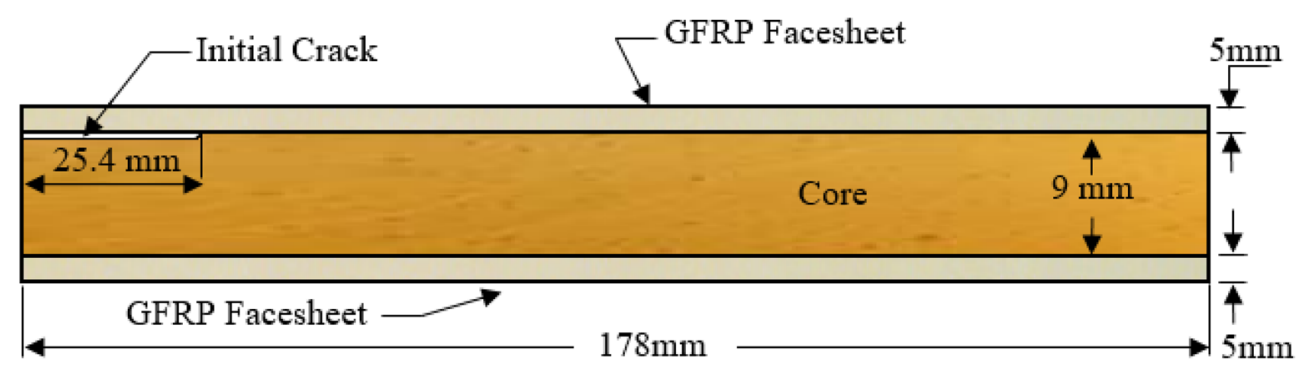

(a)

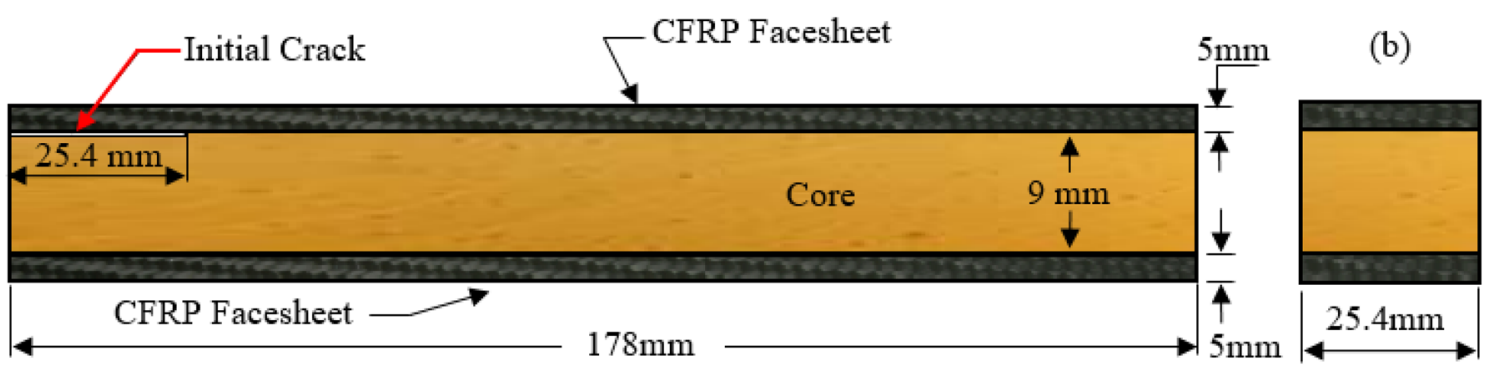

Fig. 1 Geometrical dimensions of different specimens studied

the platen for 15 min each to cool the sandwich panel to room temperature. The sandwich panels were post cured after the autoclave process in an oven at $80^{\circ} \mathrm{C}$ for $5 \mathrm{~h}$. Resin diffusion of approximately $0.5 \mathrm{~mm}$ thickness was observed from the facesheet into a core, along the length of the specimens where Teflon was not present, during the processing of sandwich panels. Later, the sandwich panels were cut into specimens having $178 \mathrm{~mm}$ length and $25.4 \mathrm{~mm}$ width using a band saw for testing. The total thickness of the samples was $19 \mathrm{~mm}$.

\section{Experimental methods}

Three- and Four-point flexural tests were conducted after referring to the ASTM standards D790 and D6272 to investigate the flexural behavior of sandwich specimens. The four-point tests were conducted to understand the effect of the addition of a fourth load-bearing point due to which a much larger portion of the beam comes under the maximum stress, whereas in the incase of the threepoint flexural tests only the material right under the central load-bearing point is under the maximum stress. As per ASTM standard D6272, procedure A is considered for applying the compressive force to the specimen at one third point loading (L/3) with load span as $41 \mathrm{~mm}$ and support span as $127 \mathrm{~mm}$ in the four-point flexural tests. MTS machine with a load capacity of $22 \mathrm{kip}$ was used to carry out flexural tests. Three and four-point bending fixtures produced by Wyoming test fixtures Inc. were utilized to conduct the experiments at room temperature. Supports and loading nose cylinders of these fixtures was having $12.7 \mathrm{~mm}$ diameter. The displacement control mode of the MTS machine was used to perform the quasi-static flexural tests by pushing the bottom
Fig. 2 Three-point and Four-point flexural test setup pertaining to GFRP/PU foam specimens
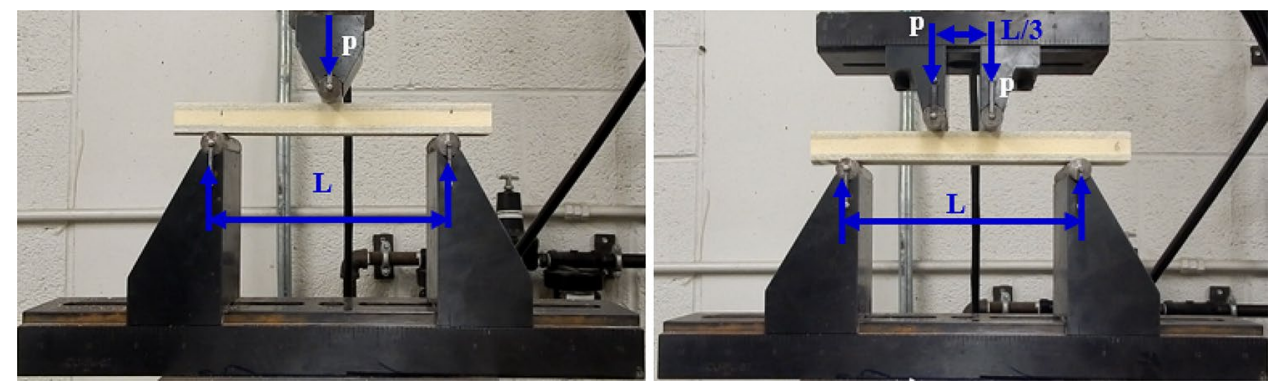
supports against the sandwich beam at a rate of $3 \mathrm{~mm} /$ min. The sampling rate at which the load, displacement, and time histories were recorded by the computerized controlled machine was $0.5 \mathrm{~s}$. To obtain useful data, six samples of sandwich beams were tested and the readings were averaged and combined into a single graph. Figure 2 shows the test fixtures and specimen configurations during the three and four-point bending tests.

In sandwich composite beams, the applied loads are mainly transported from facesheet to core by the interfacial bond. Therefore, it becomes at most vital to study the characteristics of the sandwich beams having interfacial defects. Research articles studying the performance of sandwich beams with and without interfacial defects are already available in the literature, thereby investigating it with different types of facesheets and core materials will be just duplication and withstands no novelty. The distinctive fact of the present article is that it investigates the characteristics of such sandwich composite beams having interfacial defects under both types of flexural tests i.e. three and four-point bending test methods. The presented work in this study is closely relevant to previously published research work [14],23, 24 as these articles also investigate the flexural behavior of sandwich beams having interfacial defects. However, the effect of geometric parameters such as the material of facesheets and loading conditions, etc. on their flexural characteristics is the added value of this article. Under the flexural loads, the composite beam suffers the maximum shear stress towards the ends of the specimen. The sandwich beam with interfacial defects in such region in real world scenario due to manufacturing or joining processes will be most venerable in the overall performance and failure mechanisms. Keeping this fact into attention and to investigate the worst case, the implantation of the initial crack was considered at the one end of the composite beam in the facesheet and core interface.

\section{Results and discussions}

\subsection{Effect of facesheet material}

The influence of facesheet material on the flexural behavior of sandwich beams is studied by conducting threepoint flexural tests at a support span length of $127 \mathrm{~mm}$ and loading rate of $0.05 \mathrm{~mm} / \mathrm{s}$. Specimens with geometric dimensions illustrated by Fig. 1a, b was used. The comparative analysis is carried out for specimens developed by using CFRP and GFRP materials for facesheets. The core material and the geometrical dimensions were kept similar for both categories of the specimens. The force vs displacement histories for both types of specimens is

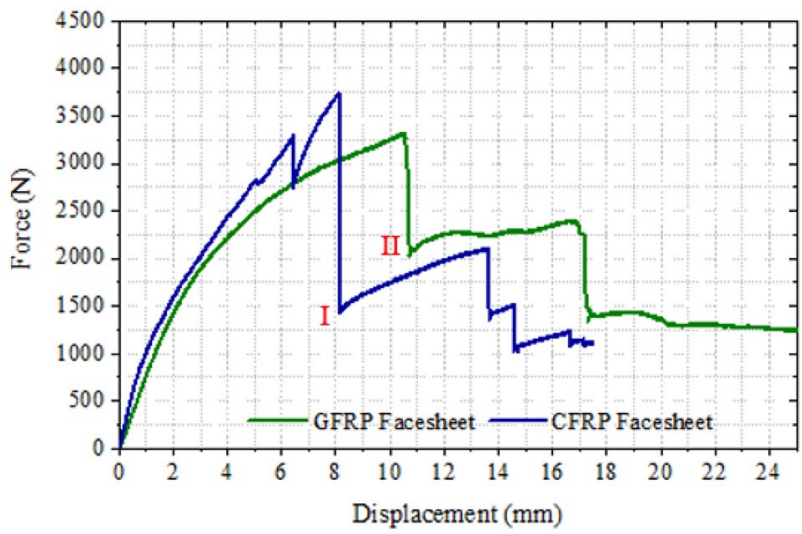

Fig. 3 Effect of facesheet material on the flexural behavior of initially debonded sandwich beams under three-point loading at support span length of $127 \mathrm{~mm}$

shown in Fig. 3. Slightly higher stiffness and peak load level were observed for the sandwich beam having woven CFRP facesheets as compared to the sandwich beam having cross ply GFRP facesheets. GFRP/PU foam sandwich beam showed higher ductile behavior prior to progressive failure of the sandwich beam. The displacement level corresponding to the first ply failure in the GFRP/PU foam sandwich beam was higher $(11 \mathrm{~mm})$ than that CFRP/PU foam sandwich beam $(6.5 \mathrm{~mm})$. The decrease in the load level after the failure of the CFRP sandwich beam illustrated by point (I) in Fig. 3 was higher than that of the GFRP sandwich beam represented by a point (II). A distinction was observed in the location of the core crack in sandwich beams having GFRP and CFRP facesheets. The crack initiated and evolved underneath the loading pin in the CFRP/PU foam sandwich beams, whereas it developed and emerged closer to one of the support pins in the GFRP/PU foam sandwiched beam as illustrated in Fig. 4a.

Table 1 shows the peak force and first failure displacement of both GFRP/PU and CFRP/PU specimens under three-point flexural loadings. The minimal scatter in the data shows the repeatability of the data.

\subsection{Effect of loading conditions}

The comparative analysis of three-point and four flexural loadings on the response of GRFP facesheet/PU foam sandwich beam under a displacement rate of $0.05 \mathrm{~mm} / \mathrm{s}$ was studied. The support span length for three-point and four flexural loading conditions was kept the same as $127 \mathrm{~mm}$ and load span length in the four-point loading case was kept as $41 \mathrm{~mm}$. Specimens with geometric dimensions illustrated by Fig. 1a was used for studying the effect of loading condition in this sub-section. The comparative force-displacement plot for two different types of 
Fig. 4 Comparative analysis of damage morphologies of the sandwich beams having GFRP and CFRP facesheets
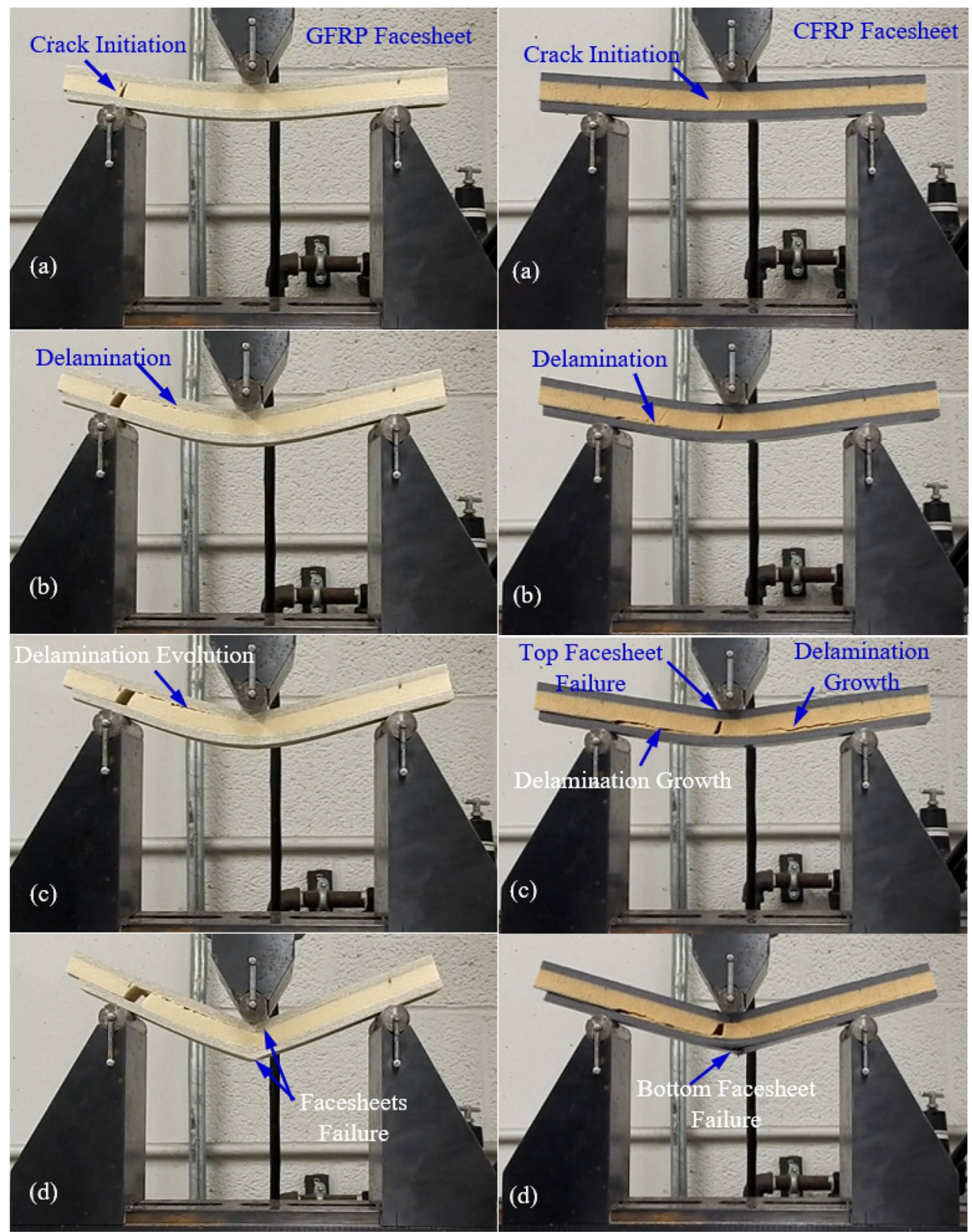

Table 1 Peak Force and failure displacement of specimens having GFRP and CFRP facesheets

\begin{tabular}{llllll}
\hline S.no. & \multicolumn{2}{l}{ GFRP/PU-specimen } & & \multicolumn{2}{l}{ CFRP/PU-specimen } \\
\cline { 3 - 3 } \cline { 5 - 6 } \cline { 5 - 6 } & Peak force (N) & $\begin{array}{l}\text { Failure dis- } \\
\text { placement } \\
(\mathrm{mm})\end{array}$ & & Peak force (N) & $\begin{array}{l}\text { Failure } \\
\text { displacement } \\
(\mathrm{mm})\end{array}$ \\
\hline 1 & 3346 & 10.5 & & 3825 & 8.01 \\
2 & 3300 & 10.4 & & 3739 & 8.1 \\
3 & 3153 & 10.4 & & 3491 & 7.5 \\
4 & 3040 & 10.55 & & 3635 & 7.8 \\
5 & 3150 & 8.6 & & 3701 & 8.0 \\
6 & 3220 & 10.1 & & 3690 & 7.9 \\
SD & 101.6 & 0.68 & 102.3 & 0.19 \\
\hline
\end{tabular}

loading on the GFRP/PU sandwich beam is shown in Fig. 5 . A similar pattern was observed in the force-displacement characteristics of GFRP/PU sandwich beams for both loading conditions; however, the four-point loading conditions resulted in higher stiffness and peak load levels because the maximum axial fiber stress is uniformly distributed between the loading noses in this type of loading condition whereas, in the three-point loading condition, the maximum axial fiber stress is located immediately under the loading nose. The displacement at which the first failure of the beam occurs is more (approx. $11 \mathrm{~mm}$ ) for the sandwich tested under three-point loading conditions than the sandwich beam tested under four-point loading conditions (approx. $8 \mathrm{~mm}$ ). 


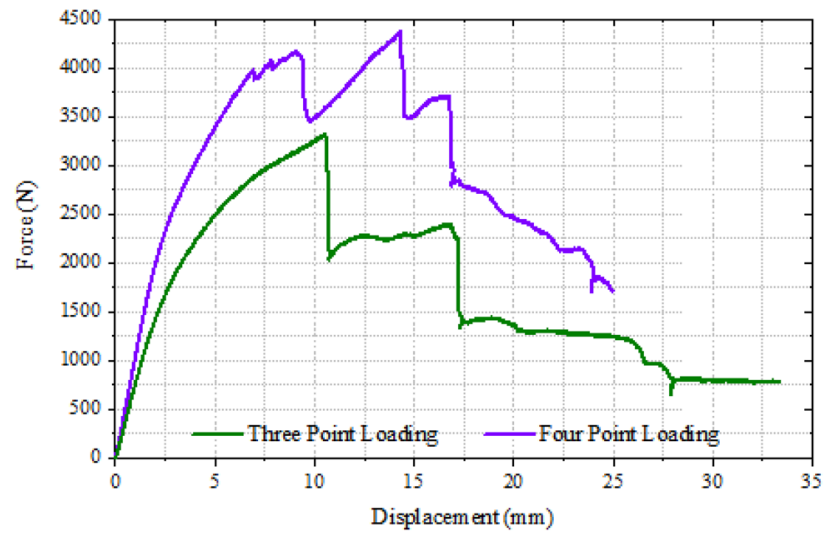

Fig. 5 Comparative analyses of Three-point and Four Flexural loading on GRFP facesheet/PU foam sandwich beam for a displacement rate of $0.05 \mathrm{~mm} / \mathrm{s}$

Progressive damage and failure were observed in GFRP/PU foam sandwich beam after the peak load in the force-displacement histories for both loading scenarios as described by Fig. 5. The comparison between the damage modes of GFRP/PU foam under three-point and four-point loading is illustrated by Fig. 6. GFRP/ $\mathrm{PU}$ foam sandwich beam shows similar typical damage modes i.e. through-thickness crack initiation in core resulting in shear failure, interfacial delamination occurrence and evolution on both compressive and tensile sides, and finally the progressive tensile failure of lower facesheet. Minimal compressive failure of upper facesheet in GRFP/PU foam sandwich beam under fourpoint loading was observed, whereas compressive failure of upper facesheet was observed in the sandwich beam under three-point loading as shown in Fig. $6 \mathrm{~d}$. After the initiation of the first failure, the load levels reduced at a higher rate in the progressive failure regime of the load-displacement plot for the four-point flexural loading as compared to the three-point flexural loading.

\subsection{Effect of span length}

The effect of span length on CFRP Facesheet/foam sandwich beam having core thickness as $9 \mathrm{~mm}$ under threepoint loading at a displacement rate of $0.05 \mathrm{~mm} / \mathrm{s}$ was investigated and compared. Three-point loading flexural experiments were conducted using span length as $127 \mathrm{~mm}, 152.4 \mathrm{~mm}, 203.2 \mathrm{~mm}$ and $228.6 \mathrm{~mm}$ in this sub-study. The geometric length dimension of specimens illustrated by Fig. $1 \mathrm{~b}$ was varied corresponding to the above-mentioned span lengths as $178 \mathrm{~mm}, 203.4 \mathrm{~mm}$, $228 \mathrm{~mm}, 255 \mathrm{~mm}$. The comparative force-displacement plot of the CFRP/PU sandwich beam for different span lengths is shown in Fig. 7. As expected with the increase in the span length, the peak load values were reduced and the initiation of the first failure instance resulting in a reduction in sandwich beam stiffness occurred at higher displacement, but it was observed that as the span-length is increased, the reduction in the load levels caused by post-peak load failure instance during progressive failure phase of the sandwich beam was reduced. The variation of span-length also affected the reduction in load level after the first failure instance; which is caused by shear failure core resulting from throughthickness crack evolution in the core; which was triggered by the presence of initial interfacial crack at the one end of the sandwich beam. It was observed that the reduction in load level after the first failure instance was reduced by a very minimal level as the span-length was varied from $127 \mathrm{~mm}$ to $228.6 \mathrm{~mm}$. This effect is also illustrated in Fig. 7 by points $A$ and $B$, where point $A$ is on the curve showing the load-displacement response of sandwich beam for $127 \mathrm{~mm}$ span length and point $B$ is on the curve representing the load-displacement histories of sandwich beam tested at span length of $228.6 \mathrm{~mm}$. As expected, since the samples have the same thickness, then span to depth ratios are higher for larger spansthis shifts higher normal stress into the facesheet. For lower ratios, the core experiences higher shear loads, and face-sheet appears to be stronger.

The comparative analysis of damage modes of CFRP/ PU foam tested at different span lengths is illustrated in Fig. 8. CFRP/PU foam sandwich beams tested at span length of $127 \mathrm{~mm}$ and $152.4 \mathrm{~mm}$ span-length shows the similar damage morphologies. The typical failure mode of the sandwich beam at these span lengths include through-thickness crack initiation in the core; resulting in shear failure of the core at extended load levels, delamination growth between core and both upper and lower facesheets, and finally, the sandwich beam fails progressively due to tensile failure of lower facesheet layers. The sandwich beams tested at span length of $203.2 \mathrm{~mm}$ and $228.6 \mathrm{~mm}$ showed identical damage morphologies. CFRP/ PU foam sandwich beam tested at these span lengths also showed through-thickness crack initiation in the core; resulting in shear failure of the core at extended load levels. The delamination evolution was also observed with the increase in the load levels at both upper and lower interfaces between core and facesheets. A distinction 
Fig. 6 Comparative analysis of damage morphologies of GFRP sandwich beam under three-point and four loading conditions

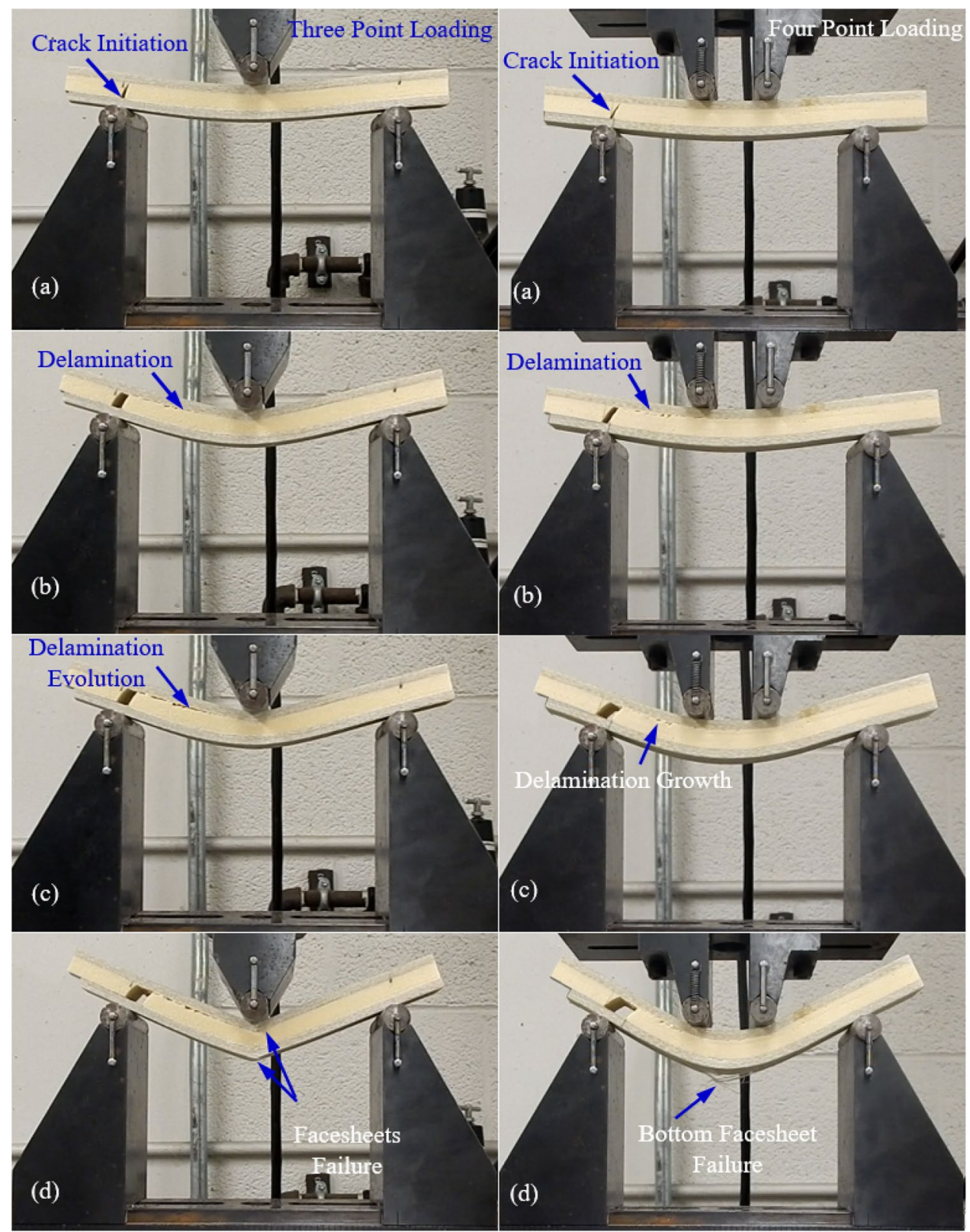




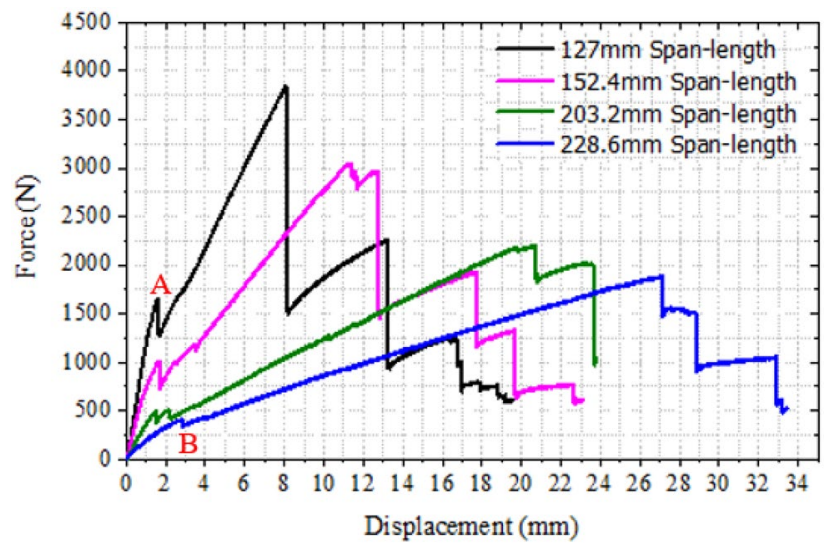

Fig. 7 Effect of span length on CFRP Facesheet/foam sandwich beam having core thickness as $9 \mathrm{~mm}$ under three-point loading at a displacement rate of $0.05 \mathrm{~mm} / \mathrm{s}$

was observed in the final failure modes of the CFRP/PU foam sandwich beams tested at span length of $203.2 \mathrm{~mm}$ and $228.6 \mathrm{~mm}$. The sandwich beam tested at smaller span length (i.e. $127 \mathrm{~mm}$ and $152.4 \mathrm{~mm}$ ) showed the tensile failure of the bottom CFRP facesheet at the final step in the progressive failure phase, whereas the sandwich beam tested at a higher span length (i.e. $203.2 \mathrm{~mm}$ and $228.6 \mathrm{~mm}$ ) showed a compressive failure of upper CFRP facesheet underneath the loading pin as a final failure in the progressive damage phase.

\section{Conclusions}

The flexural response of sandwich beams with artificial core-facesheet debond located at one end of the beam is investigated in the present research. A comparative analysis is carried out to study the effect of using CFRP and Eglass prepregs as face sheet material on such sandwich beams. Effects of loading conditions and span length were also studied by conducting both three- and four-point flexural tests. Slightly higher stiffness and peak load level were observed for the sandwich beam having woven CFRP facesheets as compared to the sandwich beam having cross ply GFRP facesheets. GFRP/ PU foam sandwich beam showed higher ductile behavior prior to progressive failure of the sandwich beam. A similar pattern was observed in the force-displacement characteristics of GFRP/PU sandwich beams for both loading conditions; however, the four-point loading conditions resulted in higher stiffness and peak load levels because the maximum axial fiber stress is uniformly distributed between the loading noses in this type of loading condition whereas, in the three-point loading condition, the maximum axial fiber stress is located immediately under the loading nose. 
Fig. 8 Comparative analysis of damage modes of CFRP/ PU foam tested at different span lengths a $127 \mathrm{~mm}, \mathbf{b}$ $152.4 \mathrm{~mm}, \mathbf{c} 203.2 \mathrm{~mm}$ and d $228.6 \mathrm{~mm}$
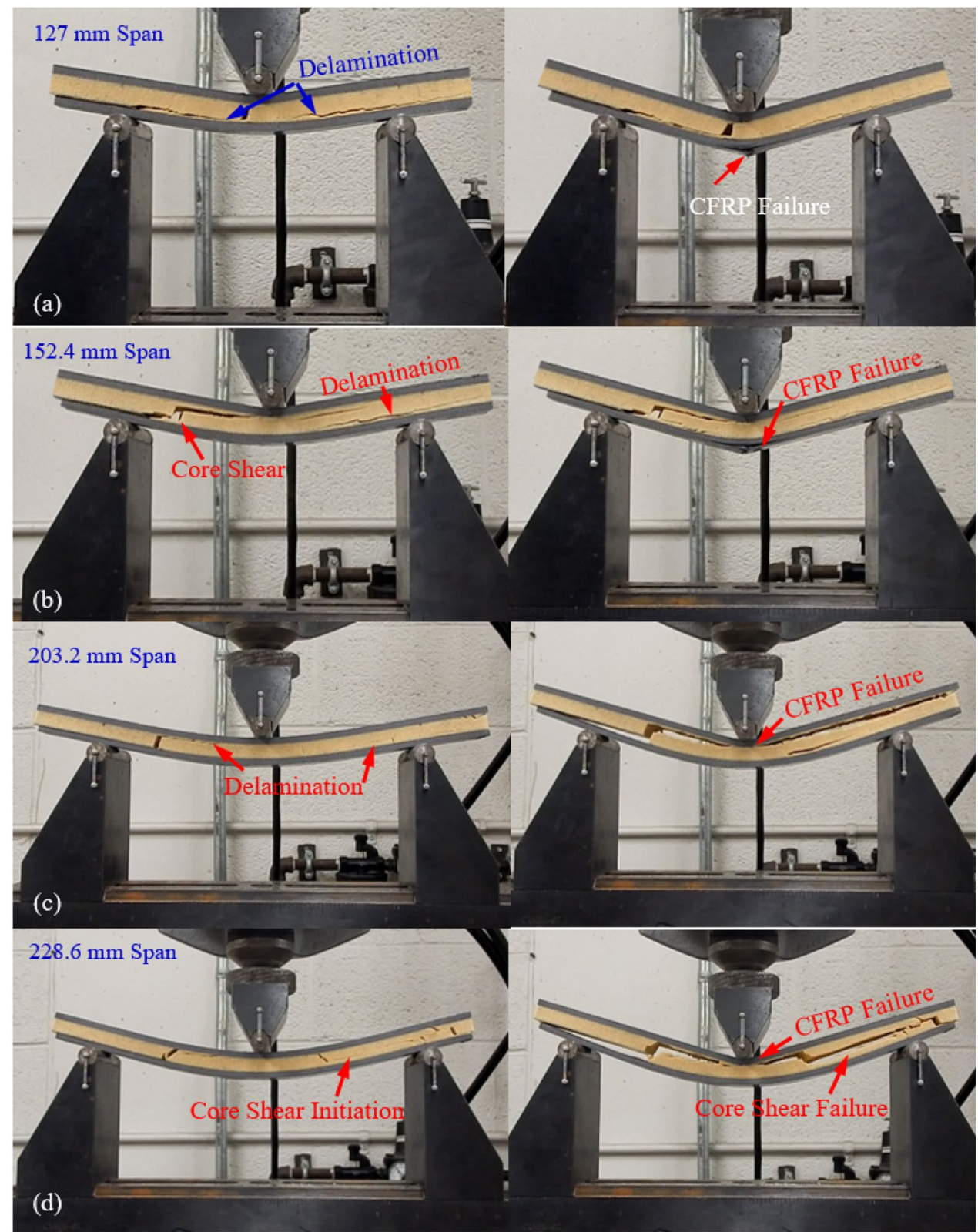

Availability of data and material Not applicable.Code availability Not applicable.

\section{Compliance with ethical standards}

Conflict of interest The author declares that there is no conflict of interest.

Open Access This article is licensed under a Creative Commons Attribution 4.0 International License, which permits use, sharing, adaptation, distribution and reproduction in any medium or format, as long as you give appropriate credit to the original author(s) and the source, provide a link to the Creative Commons licence, and indicate if changes were made. The images or other third party material in this article are included in the article's Creative Commons licence, unless indicated otherwise in a credit line to the material. If material is not included in the article's Creative Commons licence and your intended use is not permitted by statutory regulation or exceeds the permitted use, you will need to obtain permission directly from the copyright holder. To view a copy of this licence, visit http://creativecommons .org/licenses/by/4.0/.

\section{References}

1. Daniel IM et al (2002) Failure modes of composite sandwich beams. Int J Damage Mech 11(4):309-334

2. Steeves CA, Fleck NA (2004) Collapse mechanisms of sandwich beams with composite faces and a foam core, loaded in 
three-point bending. Part II: experimental investigation and numerical modelling. Int J Mech Sci 46(4):585-608

3. Manalo AC et al (2010) Flexural behaviour of structural fibre composite sandwich beams in flatwise and edgewise positions. Compos Struct 92(4):984-995

4. Caglayan C et al (2018) The effect of CNT-reinforced polyurethane foam cores to flexural properties of sandwich composites. Compos A Appl Sci Manuf 115:187-195

5. Kumar MV, Soragaon B (2014) Fabrication and evaluation of multilayered polyurethane foam core sandwich panels for static flexural stiffness. Procedia Eng 97:1227-1236

6. Barbieri N, Barbieri R, Winikes LC (2010) Parameters estimation of sandwich beam model with rigid polyurethane foam core. Mech Syst Signal Process 24(2):406-415

7. Awad ZK, Aravinthan T, Manalo A (2012) Geometry effect on the behaviour of single and glue-laminated glass fibre reinforced polymer composite sandwich beams loaded in four-point bending. Mater Des 39:93-103

8. Waddar S et al (2019) Buckling and vibration behaviour of syntactic foam core sandwich beam with natural fiber composite facings under axial compressive loads. Compos B Eng 175:107133

9. Zhang $\mathrm{F}$ et al (2019) Flexural behavior of composite sandwich beams with different kinds of GFRP ribs in flatwise and edgewise positions. Compos B Eng 156:229-239

10. Chandra MS et al (2017) Finite element analysis of glass/epoxy skin and rigid foam core sandwich composites-simulation of shear modes and flexural modes of failure. Mater Today Proc 4(8):8856-8865

11. Tuwair $\mathrm{H}$ et al (2015) Evaluation of sandwich panels with various polyurethane foam-cores and ribs. Compos B Eng 79:262-276

12. Fathi $A$ et al (2013) An investigation on the flexural properties of balsa and polymer foam core sandwich structures: Influence of core type and contour finishing options. J Sandw Struct Mater 15(5):487-508

13. Gibson RF (2011) A simplified analysis of deflections in sheardeformable composite sandwich beams. J Sandw Struct Mater 13(5):579-588
14. Mansourinik M, Taheri-Behrooz F (2018) The effect of interface debonding on flexural behaviour of composite sandwich beams. J Sandw Struct Mater. https://doi.org/10.1177/10996 36218781981

15. Mohamed $\mathrm{M}$ et al (2015) Manufacturing and characterization of polyurethane based sandwich composite structures. Compos Struct 123:169-179

16. Aslan M et al (2017) An investigation on the mechanical properties of the sandwich panel composites. In: 2nd international defense industry symposium science board, Kırıkkale, Turkey, April 2017

17. Vadakke V, Carlsson LA (2004) Experimental investigation of compression failure mechanisms of composite faced foam core sandwich specimens. J Sandw Struct Mater 6(4):327-342

18. Vadakke V, Carlsson LA (2004) Experimental investigation of compression failure of sandwich specimens with face/core debond. Compos B Eng 35(6-8):583-590

19. Aviles F, Carlsson LA (2006) Experimental study of debonded sandwich panels under compressive loading. J Sandw Struct Mater 8(1):7-31

20. Mouritz AP, Thomson RS (1999) Compression, flexure and shear properties of a sandwich composite containing defects. Compos Struct 44(4):263-278

21. Thomson RS, Khan MZS, Mouritz AP (1998) Shear properties of a sandwich composite containing defects. Compos Struct 42(2):107-118

22. Dhaliwal GS, Newaz GM (2020) Flexural response of degraded polyurethane foam core sandwich beam with initial crack between facesheet and core. Materials 13(23):5399

23. Al-Fasih MY, Kueh ABH, Ibrahim MHW (2020) Failure behavior of sandwich honeycomb composite beam containing crack at the skin. PLoS ONE 15(2):e0227895

24. Monetto I (2019) The effects of an interlayer debond on the flexural behavior of three-layer beams. Coatings 9(4):258

Publisher's Note Springer Nature remains neutral with regard to jurisdictional claims in published maps and institutional affiliations. 